\title{
A Comparative Study on Water Management Practices in India with Special Reference to Gujarat and Meghalaya
}

\author{
Naini Jain* and Neha Makkar†
}

\begin{abstract}
India is experiencing the most terrible water emergency in its history and a large number of lives are under risk. The fast development of populace joined with rising degrees of utilization and contamination has expanded water frailty in India. Meghalaya, concealed in the slopes of eastern sub-Himalayas is one of the most excellent states in the nation. Nature has favoured her with plenteous precipitation, sun-sparkle, virgin timberlands, high levels, tumbling cascades, completely clear waterways, wandering streamlets or more all with strong, shrewd and accommodating individuals. Yet Meghalaya had the lowest Water Index score of 26.This paper studies nine parameters where Meghalaya (being the worst performer with score of 26) is lagging behind from Gujarat (being the highest performer with the score of 76) in Composite Water Index. A descriptive analysis has been done and lessons gained are proposed for the management of water crisis in the state of Meghalaya.
\end{abstract}

Keywords: Water Management, Gujarat and Meghalaya, Composite Water Index

\section{Introduction}

The world's fastest growing economy is running out of water. The water crisis in India is getting worse and there is a need for all of us

\footnotetext{
* Indian School of Business and Computing (ISBC) Bangalore, India; naini@isbc.ac.in

† Institute of Innovation in Technology and Management, New Delhi, India; nehaamakkar@gmail.com
} 
to understand this crisis, our water resources, and its efficient and sustainable uses. Millions of lives and livelihoods are under threat. According to the report by Niti Aayog, currently, 600 million Indians face high to extreme water stress and about two lakh people die every year due to inadequate access to safe water. By 2030, the country's water demand is projected to be twice the available supply, implying severe water scarcity for hundreds of millions of people and an eventual 6\% loss in the country's GDP. As per the report of the National Commission for Integrated Water Resource Development of MoWR, the water requirement by 2050 in high use scenario is likely to be a milder 1,180 BCM, whereas the present-day availability is $695 \mathrm{BCM}$. The total availability of water possible in the country is still lower than this projected demand, at 1,137 BCM. Many households do not have drinking water on their premises, rural households do not have piped water access. Our water is so contaminated that India is currently ranked 120 among 122 countries in the water quality index. As water is becoming scarce and demand for it is increasing with the growing population, there is a need for a proper water management system. Proper planning, development, distribution and management of water resources is the need of the hour. We need to find a balance between the requirements of the humans and the needs of the environment for the sustainability of water resources. The Indian government has proposed to study and implement a plan to interlink 37 rivers to develop inter-basin water transfer links. This will make the water available for various purposes like irrigation, and replenishment of groundwater. It will also help in other economic benefits like employment generation, power industry, drainage systems and other socio economic aspects.(Kumar N., 2020)

\subsection{Global Partnership}

Israel, located in Asia, with most of its area being a desert land has developed a variety of solutions to desertification through desert agriculture, irrigation, desalination, aquaculture, afforestation and management of water resources. India can also implement the similar solutions for overcoming the water crisis. Indian Government has also signed an MOU with Israel to leverage 
Israel's expertise for a national campaign for water conservation in India. Israel treats $100 \%$ of its Municipal water waste.

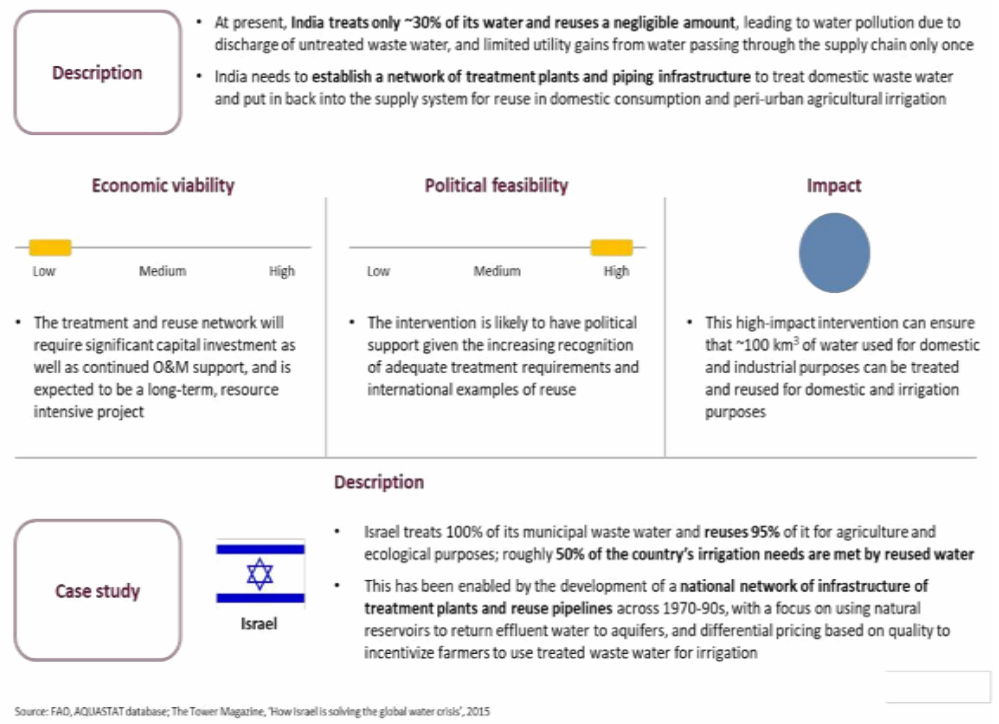

\subsection{The National Institute for Transforming India (NITI) Aayog}

The government think tank has developed the Composite Water Management Index (CWMI) to enable effective water management in Indian states in the face of this growing crisis. CWMI compares state-level performance on key water indicators.(Delberg Development advisors Pvt. Ltd, 2018) According to this index, Gujarat is the best performer in water management with a score of 76 on the index and Meghalaya is the lowest performer with a score of 26 on the index. The performance of all the states on the water management index can be seen in Table given below. 


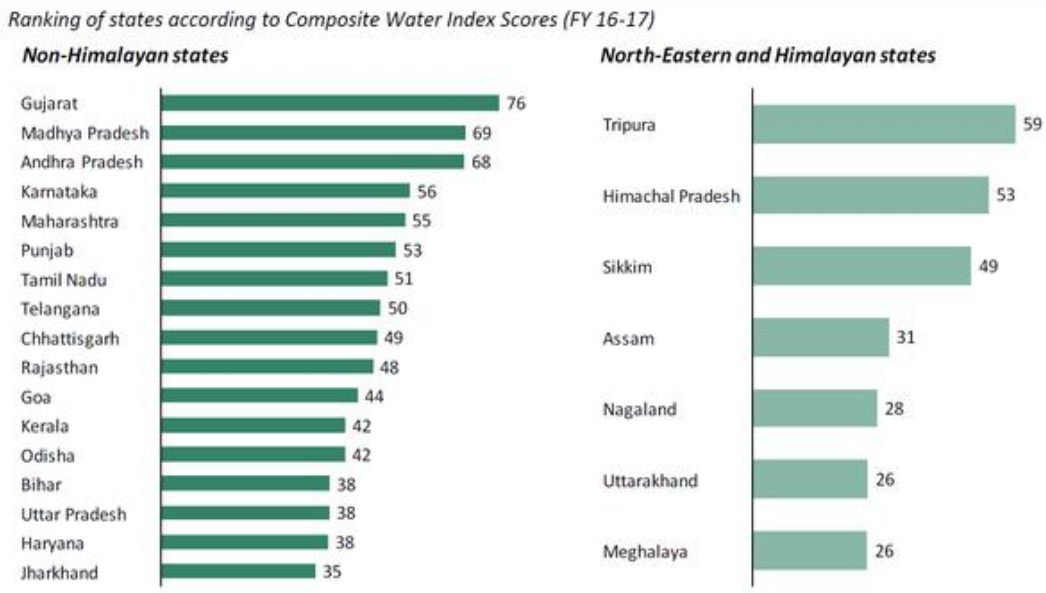

Source: niti.gov.in

The above Index (taken from Niti Aayog) explained the performance of states in water management on key water indicators. It has tried to identify the best and the worst performer. This comparison also inculcates a culture of competition among the states to perform better. As mentioned in Niti Aayog several of the high and medium performers - Gujarat, Madhya Pradesh, Andhra Pradesh, Karnataka, Maharashtra, Telangana are states that have suffered severe droughts in recent years. In the face of imminent water shortages, the actions taken by these states, and their subsequent good performance on the index, are likely driven by necessity in the face of looming water shortages. This correlation shows, positively, that corrective action is starting in some of the areas where it is needed the most.

Gujarat is a Non-Himalayan state and Meghalaya is a north-eastern state, both have different hydrological conditions. Even though Meghalaya receives an average annual rainfall of $2818 \mathrm{~mm}$ while Gujarat receives only $1107 \mathrm{~mm}$, it has not performed well on the water management index. Meghalaya with a score of 26 on the index significantly needs to improve its water management practices. In this paper, we have tried to identify the reasons for Gujarat being the best performer and Meghalaya being the worst performer in water management. 


\section{Literature Review}

Gujarat has used traditional wisdom with modern solutions for contemporary problems. The users in India have a preference for water coming from traditional systems as these systems are adapted well to the local conditions. (Bishnoi, Prateek, Sahay, \& Gupta, 2011)

There are numerous water problems that are not restricted to a single country but rather have a global presence.A large amount of water is needed for irrigation as well to ensure an adequate supply of food grains for the urban and rural populations. Problems of water pollution of surface water as well as of groundwater resources due to infrastructure development, indiscriminate use of water are some of the issues that the whole world is facing nowadays (McNabb, 2019).

Although the north-eastern region of India is a water surplus region, it still faces a lot of issues and challenges in the sustainable management of its water resources. The region faces issues in the provision of water for drinking, domestic purposes, irrigation, biodiversity conservation and other environmental uses. Some areas are also marked by the occurrence of floods and riverbank erosion. At the policy front, adoption and successful implementation of integrated water resources management (IWRM) principles and strategies could contribute significantly towards addressing the water-related problems and issues in the north-eastern region of India (Abhik, 2018).

Government policies, as well as local communities, are responsible for the replenishment of groundwater. Local communities have done efficient management of groundwater by undertaking several projects which will probably act for the aquifer replenishment in terms of increasing groundwater storage in future times and optimistically transform India from a "groundwater-scarce" to a "groundwater-sufficient" country. (Mukherjee \& Bhanja, 2019)

\section{Research Objective}

An attempt has been made to understand the water crisis that India is going through with the major focus on water management 
practices of Gujarat and Meghalaya. The research objective is to do a comparative analysis between Gujarat (best performer) and the Meghalaya (worst performer) on the water management index. This paper has been framed to understand the practices adopted by Gujarat to manage water issues.

\subsection{Research Methodology}

The paper is based on descriptive research where data was collected through varied government reports like NITI AAYOG, ENVISTATS INDIA 2018, etc. The analysis method relies on 9 parameters where discrepancies were analyzed and reports were developed after the examination and verification of the information were done.

\section{Research Analysis}

\subsection{Urban water supply and Waste water treatment}

According to the World Health Organization study, 93\% of India's urban population has access to basic water but there has been a sharp rise in inter-state as well as inter-city inequities. According to the World Bank report, 21 major cities like Delhi, Bangalore will soon reach zero groundwater levels affecting the major population of the country. This indicator measures the access of urban water supply to Gujarat and Meghalaya. Gujarat is able to supply $100 \%$ of drinking water to its urban population whereas Meghalaya is able to successfully serve more than $80 \%$ of their urban population.

Water contamination is a challenge in India which likely affects $75 \%$ of the total population. Gujarat has taken an initiative to treat urban water waste and has installed $71 \%$ of the capacity to treat wastewater. With this, they generate 3,750 million litres per day. This means that they have managed to have treated $58 \%$ of the wastewater. However, the major drawback seen in the state of Meghalaya is that it has neither installed nor treated any wastewater.

\subsection{Rural drinking water}

This indicator measures the access of rural drinking water to various Himalayan and Non-Himalayan states. Gujarat has 
performed well by covering $100 \%$ of its rural habitations. However, Meghalaya has performed poorly in providing access to rural drinking water by covering only $16 \%$ of rural habitations in the FY 2016-17 which has also declined from 17\% in the FY 2015-16.

\subsection{Watershed Development - Supply Side Management}

This indicator measures the number of water harvesting structures constructed or rejuvenated as compared to the target which sanctioned in projects under Integrated Watershed Management Programme (IWMP), Rashtriya Krishi Vikas Yojana (RKVY) and Mahatma Gandhi National Rural Employment Guarantee Scheme (MGNREGS). The basic purpose of having these programmes is the rehabilitation of existing water dams like ponds, dams, etc., resulting in an increase in irrigation potential for the small farmers and reduction in water variability for local communities. While Gujarat has constructed $81 \%$ of its target structures of the scheme Meghalaya has achieved only $61 \%$ of its target structures of the IWMP, RKVY and MGNREGS scheme (Meghalaya Basin Development Authority, 2014).

\subsection{Geo-Tagging: Water Conservation}

Geo-tagging is an important parameter as it enables water data monitoring. It is an important step towards a data-rich ecosystem for water conservation assets like recharging groundwater, restoring surface water bodies, etc. States like Gujarat have created 120,698 assets which are $48 \%$ of assets created under IWMP geotagged states. In contrast, Meghalaya has created only 5,568 assets which are $35 \%$ of assets created under IWMP geo-tagged states.

\subsection{Participatory Irrigation Practices}

WUA is an association that group local farmers who pool together financial and operational resources for the maintenance of irrigation systems. $80 \%$ of the Indian states have involvement of the Water User Association (WUA). However, states like Meghalaya, Tripura have not incorporated this association. WUA also collects an irrigation service fee to ensure the maintenance and improvement of irrigation systems, while also reducing excessive use of water in practices such as flood irrigation. Fifty percent of the service fee is collected and retained by WUA from Gujarat for 
participatory irrigation practices but no fees were collected from north-eastern Himalayan states like Meghalaya. This has encouraged the use of inefficient practices such as flood irrigation in the state. Hence, it is very important for Meghalaya to encourage the efficient use of water on the farm.

\subsection{Agriculture and Quantity of Rainfall}

The primary source of livelihood for the people of Meghalaya is agriculture. However, as per the minor irrigation projects which is implemented by the Government is only 54,000 hectares out of the total approximate 2.2 lakh hectares of net sown area. Agriculture in Meghalaya is still followed as a traditional "jhum" or rotating cultivation and unscientific extraction of minerals. This results in depletion of soil moisture, infiltration and groundwater loss. The cultivated area is only $10 \%$ of the total land and the rest are forest (utilizes maximum groundwater) which is under the government (Meghalaya Basin Development Authority, 2014). This factor has led to a deficit in food grains in the state by 122,000 tons annually. Furthermore, $75 \%$ of the agriculture land is dependent on rainfall and only $15 \%$ of the cultivated area is irrigated. The irony is that the maximum number of the villages is placed at the top of the hills, while water assets like streams and rivers float at the lowest of the hills resulting in the non-utilization of water.

Meghalaya receives the highest amount of rainfall with an average of 2,818 mm. However, Gujarat receives only 1,685 mm of average rainfall which is only $59 \%$ of what Meghalaya receives. Even though the state receives heavy rainfall in the monsoon season, the water is wasted as floor runoff that drains to the neighboring states and to Bangladesh. This, in turn, results in the decimation of woodlands and shortage of drinking water during winter months. Furthermore, due to excessive rainfall and the problem of water logging, Meghalaya is at a higher risk of soil erosion and loss of soil fertility which would result in loss of agriculture.

\subsection{Augmentation of Groundwater and Restoration of Water Bodies}

Meghalaya is developing in an unplanned manner. In Shillong, where a lot of urban growth has been seen, this unplanned 
development is creating pressure on water resources as the infrastructure is not sufficient to serve all urban dwellers. Furthermore, there are lots of unregulated wells and untreated sewage which is polluting the water bodies and affecting the groundwater table. According to Central Ground Water Board (CGWB): Systems of Meghalaya, 2012 the annual domestic and industrial water requirements up to 2025 are estimated as 0.096 billion cubic meters as per census 2001, and 1.014 billion cubic meters of groundwater can be utilized for irrigation. But according to the survey of CGWB, only $18 \%$ of the Aquifer available groundwater is being utilized and groundwater development is less than $1 \%$. Thus, there is an urgent need for groundwater development. The state has a groundwater capacity of 1226.44 million cubic meters (MCM) out of which just 1041.99 MCM is used for the water systems. By and by, there exists around $3300 \mathrm{~km}$ length of streams, 8400 hectares of supplies, 3734 hectares of tanks and lakes, and 390 hectares of swamps in Meghalaya. Meghalaya is blessed with bountiful water resources like the left bank of Brahmaputra basin $\left(11220.11 \mathrm{~km}^{2}\right)$ and the Brahmaputra tributaries basin which is yet to be explored.

However, water bodies especially Jaintia Hills are severely affected where unorganized mining activities like coal contaminate water resulting in the problem of drinking water. Furthermore, due to water pollution, many of the aquatic species have become extinct. Currently, many perennial rivers and streams have become dead rivers, especially in Jaintia Hills.

Therefore, there is a huge need for developing groundwater and restoring the water bodies. Gujarat has worked upon 34 water bodies and approximately $80 \%$ of the water bodies have been restored. In contrast, Meghalaya who came up with the policy of restoring Umiam lake has only allocated money to it but no work has been done yet. As the prevalence of rainfall is very high in Meghalaya, rainwater harvesting is another feasible choice to increase the water supply. 


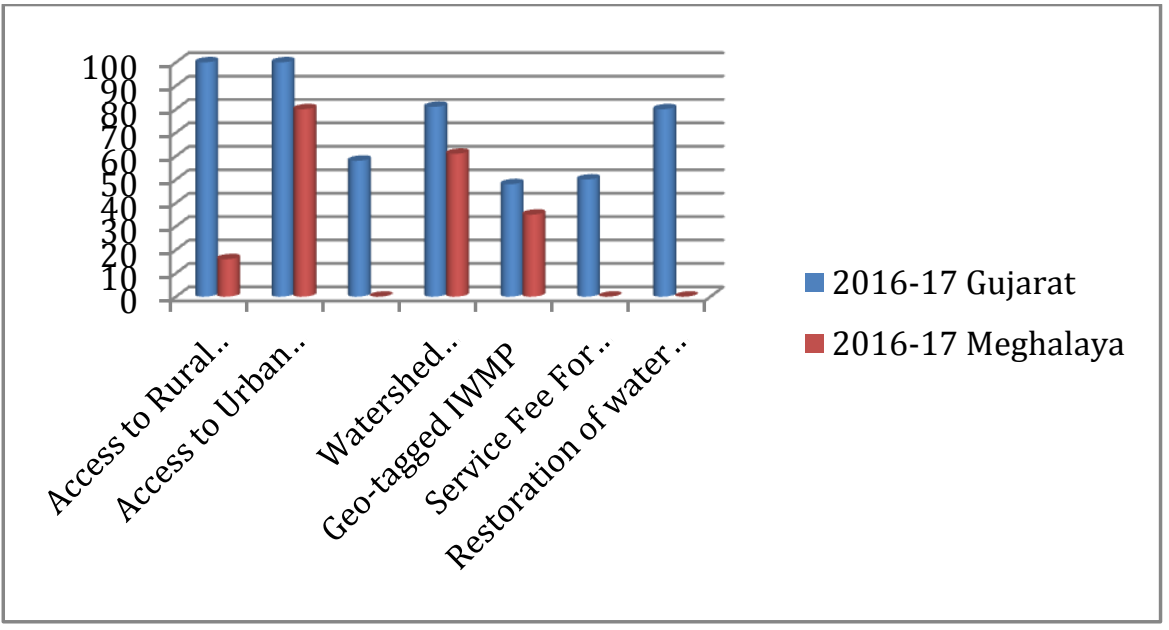

Fig 1: Seven parameters for analysis (in percentages).

\subsection{Initiative by the Government for Rainwater Harvesting in} Public and Private Buildings

It's very crucial to enforce the legislation of rainwater harvesting and restoration of water bodies as many urban regions are going to walkout of groundwater substances very soon.

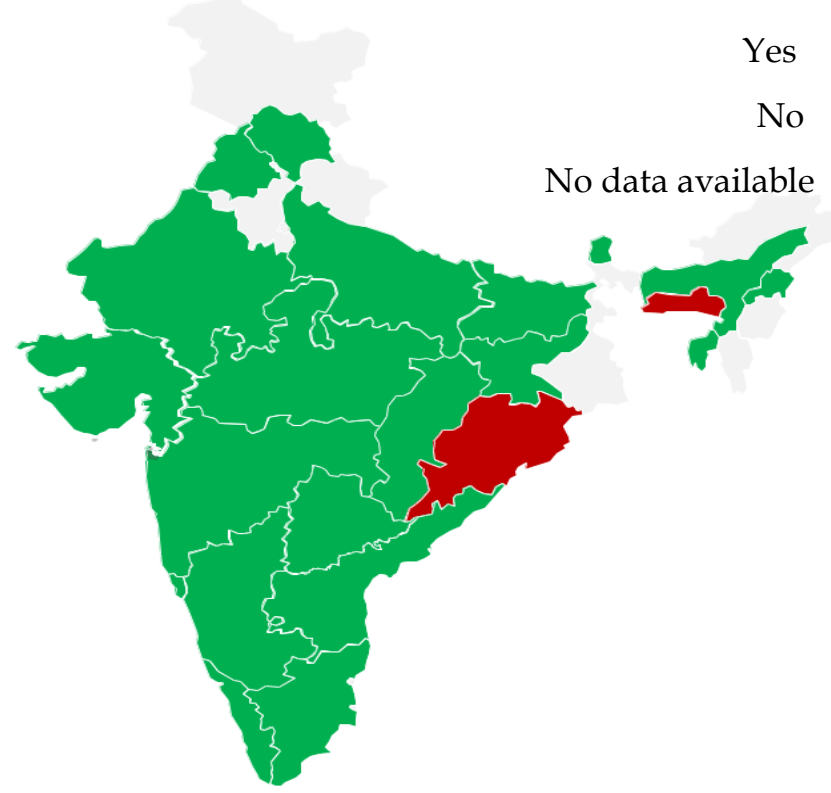


As seen in the above figure $90 \%$ of reporting states (20 out of 22 ) have finished rainwater harvesting in public and personal buildings. Gujarat too has implemented rainwater harvesting techniques but Meghalaya has not taken any initiative so far for creating a reservoir for rainwater or harvesting it. It is important to institutionalize the conservation of groundwater with the aid of setting up a clear regulatory framework. The massive enactment of rainwater harvesting legislation additionally bodes nicely for the sustainability of urban regions which could soon run out of groundwater resources.

\subsection{Integrated Data Center for Water Resources}

This indicator helps in checking whether the state has its integrated data centre for water resources and is it being updated regularly or not. Integrated data centre is crucial for every state to properly examine and resolve the water issues through focused policymaking and broader ecosystem innovation.

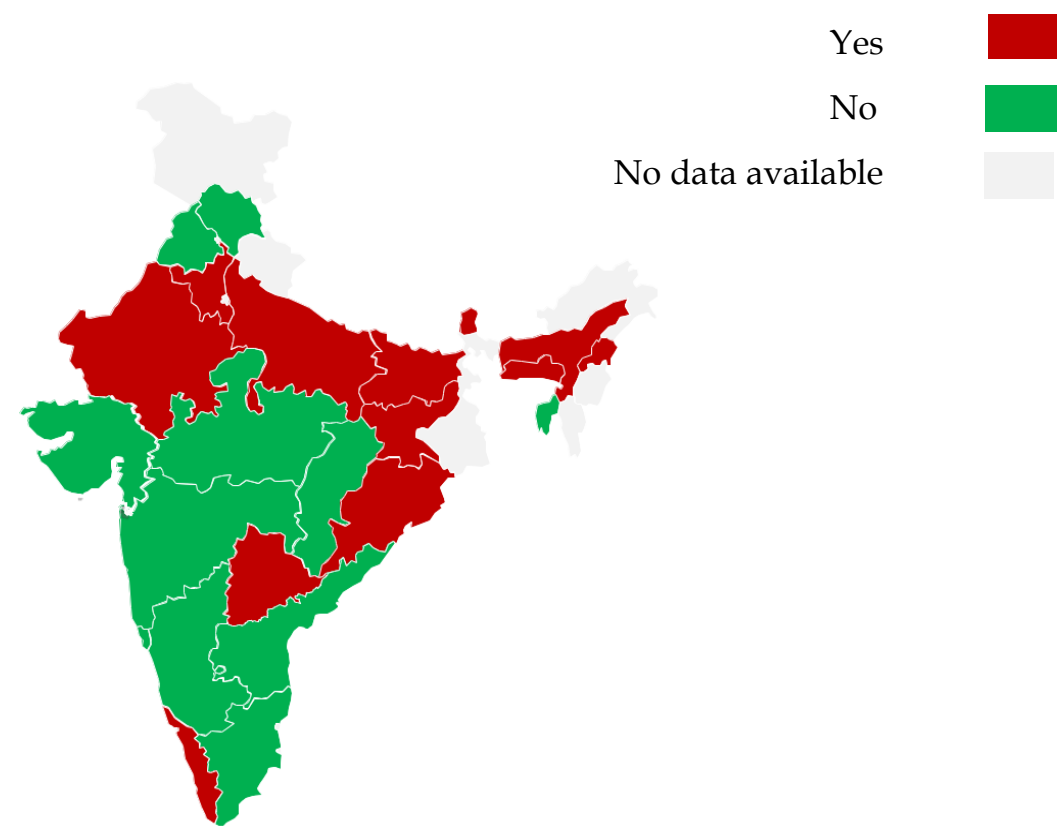

As seen in the above figure $50 \%$ of states have established integrated water information centres, and people are updated frequently. Gujarat too has incorporated integrated data centre but Meghalaya is lacking behind in this indicator as well. This data 
centre should be incorporated in all the states as it will permit targeted policymaking collectively with agricultural incentives and groundwater recharge. Apart from this, a data center is important for the records that can be made available on a public platform for researchers, entrepreneurs, NGOs, and policymakers to use it to create innovative products, offer value-delivered offerings, and format targeted policies and interventions.

\section{Conclusion}

The availability of groundwater is abundant in Meghalaya but due to water contamination (mainly due to coal mining and industrial wastages) and lack of awareness in masses, there is depletion in water resources. For developing the groundwater pene plain surfaces, buried pediments and the valley fills are the most favorable locations. The fractured rocks and lineaments also maintain prospects for the improvement of groundwater. Furthermore, the slim and linear valleys maintain enough scope of development of groundwater.

A major part of the land in Meghalaya is beneath the person ownership (Sarma, 2010). Very small vicinity is under the authority's control that is primarily beneath the forest cover. For this reason, there are difficulties in locating land for a pilot venture related to restoration of water bodies by the manner of building of wetlands and structures for limestone remedies to neutralize the acidity and development of water quality. The government should develop projects for periodical assessment of the groundwater in consideration with the quality of water available as done in Gujarat. Furthermore, scientific crop management should be incentivized so that drought tolerant crops can be developed. States like Gujarat, Maharashtra, Madhya Pradesh and Andhra Pradesh (reuse $94 \%$ of their water) make their rural and urban masses aware not only about the scarcity of water but also about limiting and reusing the water in an effective manner to significantly bridge the supply-demand gap. There is an urgent need for volunteers for restoration activities and construction of rainwater harvesting facilities to restore water. 
Naini and Neha A Comparative Study on Water Management Practices in India

\section{References}

AAYOG, N. (2018). Composite water management Index.

Bishnoi, S., Prateek, G., Sahay, N., \& Gupta, A. (2011). Traditions Of Water Conservation, Sanitation And Augmentation: Insights From Gujarat. Plurimondi, 91-121.

Chitravanshi, R. (2017, April 06). 8 states declared drought affected, Centre allows them to offer 50 days of extra work under NREGS. Economic times.

Das Gupta, S., Tiwari, B., \& Tripathi, R. (2002). Coal Mining in Jaintia Hills, Meghalaya: An Ecological Perspective. (P. \&. Passah, Ed.) Reliance Publishing House, New Delhi.

Gupta, A. (2018). Integrated Water Resources Management in the Biodiversity-rich, high rainfall, northeastern region of India: Issues and challenges. In environmental, industrial and energy safety -2018, 1821.

Gupta, A. (2018). Integrated Water Resource Management In The Biodiversity-Rich, High Rainfall, Northeastern Region of India: Issues And Challanges. - 2018, (pp. 18-21).

Kumar, N., \& Verma, A. (2019). Inter-basin Water Transfer and Policies of Water Resource Management. Springer, Singapore.

McNabb, D. E. (2019). Alternative Sources of Water Supply. In Global Pathways to Water Sustainability, 251-262). Palgrave Macmillan, Cham.

Meghalaya Basin Development Authority. (2014). In Conversation with People of Meghalaya- Water Mission.

Ministry of Water Resources. (2012). Repair, renovation and restoration of water bodies. Government of India.

Mukherjee, A., \& Bhanja, S. N. (2019). An untold story of groundwater replenishment in India: impact of long-term policy interventions. Springer, Singapore.

Singh, S. S. (n.d.). Status of water quality in coal mining areas of Meghalaya, India. Institution of Public Health Engineers.India, 173-181. 